THE JOURNAL OF TEACHING ENGLISH FOR SPECIFIC AND ACADEMIC PURPOSES Vol. 6, No 3, 2018, pp. 365-375

UDC: 811.111 '255.4:378.147/124 https://doi.org/10.22190/JTESAP1803365W

\title{
EXPLORING ACADEMIC WRITING WITH GRICE
}

\author{
Mark Wyatt ${ }^{1}$, Roger Nunn ${ }^{2}$ \\ ${ }^{1}$ Khalifa University of Science and Technology, Abu Dhabi, UAE \\ E-Mail: dr.markwyatt@gmail.com \\ ${ }^{2}$ American University of Sharjah, Sharjah, UAE \\ E-Mail: rogercnunn@yahoo.co.uk
}

\begin{abstract}
While the organization of most academic writing courses around the introduction and practice of discrete linguistic elements might suit those learners who adopt a more atomistic approach to language learning, this approach might not be so appropriate for those learners searching for a more holistic understanding. For the latter group, a course centered on a pragmatic view of discourse, and drawing on Gricean maxims, which can provide a framework within which features of genre-specific academic writing can be explored, might be appropriate. Such courses remain rare. Where they are provided, they might be evaluated with the help of students' reflections on their learning, which can provide insights that facilitate subsequent course development. Set in a largely curriculum-free Middle Eastern university context in which Gricean maxims had been previously employed in the teaching of academic writing, this study reports on one such course developed through negotiation with students. It analyses students' reflections on which aspects of the input they had found most salient and why. Benefits of the course, in terms of students' awareness of how their conceptions of academic writing had developed through critically evaluating a chosen text using Gricean maxims as a framework, are highlighted.
\end{abstract}

Key words: pragmatics, Gricean maxims, academic writing, critical analysis, Middle East

\section{INTRODUCTION}

While it is generally accepted that the role of a teacher of English for academic purposes includes supporting the development of coherent writing, 'coherence' remains for many "an abstract and fuzzy concept [which] is difficult to teach... and learn" (Lee, 2002, p. 135). This may be partly because, as Lee explains, some researchers consider coherence as internal to the text and others as internal to the reader. Amongst the latter group, Lee continues, there are those who hold an "interactional theory of coherence" shaped by a pragmatic view of discourse centered on Grice's (1975) Co-operative Principle, "that is, that the writer has a benign intention in writing and the reader intends to co-operate" (p. 138). Amongst researchers holding such an interactional theory of coherence is Nunn (2006), who highlights that while McCarthy (1991) finds no role for Gricean pragmatics in language teaching, in his view an understanding of Grice is essential for language teachers since their work is concerned with supporting pragmatic language use in learners who are engaged holistically in negotiating communication in their own social contexts. From this perspective, an understanding of Gricean pragmatics can help language teachers organize their teaching.

In accordance with the Co-operative Principle, Grice (1989) developed the following maxims: "Make your contribution as informative as is required [but] not... more informative than is required"; "try to make your contribution one that is true"; "be

Submitted July $26^{\text {th }}, 2018$, accepted for publication October $12^{\text {th }}, 2018$ 
relevant"; "be perspicuous", i.e. clear (pp. 26-27). These maxims are labelled respectively "Quantity, Quality, Relation and Manner" (p. 26). If followed, they support the cooperative exchange of information and influence, Grice argues. This is not to suggest, though, that they are rules to be followed blindly. Grice points out that they are contextdependent and that skilled communicators often flout them deliberately, opt out or violate them. Unskilled communicators, however, can appear inept by failing to work out what is required to further the cooperative exchange of information and influence as their argumentation develops, and this is where the maxims have special relevance to the language teacher aiming to support the coherence of their students' output (Nunn, 2006, 2009).

While originally developed with conversation in mind, Grice's (1989) maxims have been applied to the analysis of writing in English that has been produced for commercial (e.g. Tseng, 2015) and academic purposes (Abari \& Lofti, 2013), and to the teaching of writing in English as a second or foreign language in academic contexts (e.g. White, 2001; Nunn, 2009). Within these studies, there are different interpretations of Grice's (1989) maxims; for example, while Nunn and Deveci (in press) recognize that the writer always has options rather than a set of rules, Abari and Lofti (2013) present a far more rigid interpretation, one that does not seem to have been intended in Grice's (1989) theory. The maxims, as understood here, are seen as principles for the author to consider while drafting any socially-oriented text and each stage thereof; Grice suggests that through these changing stages different applications of the maxims may be required.

In developing their unifying analytical frameworks, several of these researchers have combined use of Grice's (1975) Co-operative Principle with other principles. For example, Nunn (2009) refers to Wittgenstein's (2001) notion of language games in relation to genre, suggesting that the way maxims are applied depends on the language game being played (e.g. research methodology section of a paper, research abstract). Meanwhile, in the context of analyzing creative product descriptions, Tseng (2015) draws upon Leech's (1983) Interest Principle as a way of explaining how the Quality maxim is sometimes flouted in such discourse. Tseng also explains, though, that the Interest Principle intersects with the Relation maxim, and in academic writing one can perhaps assume less conflict between the Interest Principle/Relation and Quality than in advertising. In academic writing, in seeking to demonstrate that their work is innovative (and therefore relevant), authors might be seeking to build upon what has gone before; they are thus proposing new knowledge in relation to that which is known (Nunn \& Deveci, in press). While doing this, they are referencing according to their purposes (Thompson \& Tribble, 2001), seeking to establish both relevance and trust.

Grice's (1989) maxims do seem to provide a particularly appropriate framework to support the analysis of academic writing, as White (2001) argues. Various other relevant theories can be subsumed within this framework. An awareness of genre analysis (Swales \& Feak, 2009), for example, can support interaction with and development of each section of the text; this relates to the Quantity maxim. It is important to remember, though, that the author always has choices, as Nunn and Deveci (in press) remind us; genre analysis can support an understanding of how much information might be expected in relation to different moves within each section, but the author might have very good reasons for flouting the Quantity maxim too.

Regarding Grice's (1989) maxim Manner, this is actually flouted frequently in academic writing, partly as a consequence of this too often being taught as a "uniformly 
impersonal... alien form of literacy" (Hyland, 2002, p. 351). As Hyland goes on to explain, by outlawing first person pronoun use in favor of impersonal structures and the passive, the teachers of academic writing who do this are actually harming their students; they are inhibiting them from expressing their ideas clearly. Students need to be able to make appropriate choices regarding use of the active or passive and first person pronoun use or impersonal structures, given the specific discipline and what they wish to say. Writing in a clear manner can also of course be supported in other ways, for example through an encouragement to eliminate or reduce jargon.

Regarding Grice's (1989) maxim Quality, an important way in which an academic text can fulfil this is through appropriate use of modality. As Hyland (1994) explains, the use of hedging through devices such as modal auxiliary verbs, and modal adjectival and adverbial expressions, allows authors to demonstrate their level of confidence in the propositions they are expressing. If there seems insufficient modality in the authors' words, therefore, or if the hedging they employ seems excessive, this might weaken the confidence of the reader in the trustworthiness or quality of the research. Of course, other features of the academic text might also contribute to its trustworthiness, including evidence of peer review.

The use of Grice's (1989) maxims, therefore, seems to be one basis for the organization of an academic writing course for undergraduates, such as that described below. However, additionally, any such course should be sensitive to culture and context; White (2001) highlights, for example, that the quantity of information expected in a business letter produced in Eastern Europe might be very different from that considered appropriate in the UK. Almalki (2015) demonstrates that Saudi students embarking on further studies in Australia might have different conceptions of relevance to their western-educated university professors, and suggests both sides could adjust their expectations. While this might be desirable, perhaps a harsher reality is that, in numerous international higher education contexts, students are needing to adapt to 'Englishization', with Western-educated professors and materials in English. Such students need to be able to make decisions about what is worth reading and pursuing with and what is better to discard. And if they can understand how texts that are valued in the international community communicate, it is more likely that they can apply this understanding in producing academic writing that is considered coherent by different audiences. Exploring coherence in academic writing through a framework provided by Gricean maxims might be of particular benefit, too, to more holistically-oriented learners, particularly those who have previously received more atomistically-organized input based on the discrete development of relatively decontextualized areas of academic knowledge and skills.

\section{THE COURSE}

In a largely curriculum-free environment in September 2017, I (the first author) was asked to teach an undergraduate English and Communication 2 course (for first-year students in their second semester at a university of science and technology in the Middle East). The stated aims of the course were to develop writing, reading and analytical skills, and the syllabus stipulated that the assessment included 50\% research project and 50\% coursework. Within this framework, I was free to negotiate the curriculum with the students. 
Initial discussions revealed that, while the students had been introduced to academic essay-writing through input that sounded atomistic, they were largely unfamiliar with research; they were generally unclear about not only conducting primary research but also systematic secondary research involving the analysis of academic articles. Indeed, in their previous English and Communication 1 course, they reported they had tended to gain input for their essays on humanities and social sciences topics through general Internet searches of the 'why are human rights important?' type. Given this relative lack of research experience, their request, while we were negotiating the English and Communication 2 course syllabus, that they conduct literature reviews, but with more academic sources, rather than engage in primary research projects, seemed reasonable.

The negotiated syllabus involved the students first, working in small groups, in collaboratively identifying a project involving secondary research with a title that was sufficiently sophisticated to allow them to engage through teamwork; context-specific humanities and social sciences topics they chose included developing understandings of mental illness, social consequences of artificial intelligence, social effects of digital piracy, the impact on individuals of advertising, and alleviating poverty. The students then needed to identify academic articles that they could use together for this project and prepare a proposal. Next, each student needed to select one of their group's articles to analyze in depth, to work on through five successive individual assignments; the first four of these titles were based on Grice's (1989) maxims of Quantity, Relation, Manner and Quality, followed by a 'reflection'. The students then worked collaboratively on their literature reviews and made presentations.

The English and Communication 2 course described above shares some similarities with others previously developed in the same national context. For example, for a semester-long project-based communication course involving students in tasks such as evaluating academic sources, and then developing literature reviews, producing research proposals that led into primary data collection, drafting progress reports leading into final reports, and finally making multimedia presentations, Nunn (2009) drew upon Grice's (1989) maxims for the source evaluation assignment to support a critical reading of texts. While I did not have access to information about Nunn's (2009) course at the time of developing my own course in 2017, Grice's (1989) maxims had also been drawn upon in the development of a postgraduate technical and scientific academic writing course at the same university (Nunn \& Deveci, in press). Having also, since 2016, taught this postgraduate course, which had been developed by Roger Nunn, I was able to draw inspiration from it.

Similarities between my course and that described by Nunn and Deveci (in press), for postgraduates, included making Grice's (1989) maxims central to the learning/teaching process, and engaging students in both analyzing texts with reference to these maxims, and then subsequently producing academic writing that was ideally imbued with an understanding of these maxims. However, the English and Communication 2 course was also quite different from that of Nunn and Deveci (in press), in that it was designed for first-year undergraduates rather than postgraduates and drew on more general humanities and social sciences topics rather than scientific topics to reflect the students' academic level and interests; it was also much more time-intensive, as a 4-credit rather than a 1credit course.

To provide some insights into the pedagogical approach adopted, I briefly describe below how the students were introduced to Grice's (1989) maxims. This was done 
indirectly, with the help of two carefully chosen journal abstracts, which were labelled Text A and Text B, and distributed more or less evenly to the class of 19 students. Working in groups of three or four, the students analyzed one of the abstracts (Text A, which was Arumugam et al. [2013] or Text B, which was Beddoes \& Panther [2017]), and then paired up with a student from another group, who had focused on the other abstract. The students compared notes and then (basing their answers on previous experience, and informed that there were not necessarily clear 'right' or 'wrong' answers) answered the following questions together:

1. Which abstract seems to make more effort to demonstrate why the research is relevant and needed?

2. Which seems to be better structured and balanced, giving a more appropriate level of detail?

3. Which seems to be clearer?

4. Which do you trust more and why?

In feedback, it was highlighted that one of the abstracts (Text A) did not appear to establish relevance very well at all; it started by indicating what the study investigated, but gave no indication as to why this focus had developed. I told the class that as a reader I might be interrogating the authors if they were present: "So what's the importance of this topic? Why did you bother to carry out this study?" In contrast, we could agree that Text B fairly skillfully provided sufficient background information at the outset to demonstrate that the research was needed and was innovative.

Imbalances in the structure of Text A were also picked up by the class; this abstract contained detailed findings that somehow seemed to miss the big picture and, we agreed, would quickly be forgotten if the reader chose to engage with the whole article. In contrast, while we felt Text B could have provided slightly more information about the findings, we agreed that this abstract seemed better balanced, and I pointed out that it contained moves (Swales \& Feak, 2009) the reader familiar with journal article abstracts would anticipate; these moves were outlined.

Regarding clarity, I highlighted that there were sentences in Text A that did not seem to make sense; this text also appeared to make inaccurate use of a methodological term, and there was a spelling mistake: "tringulate" (Arumugam et al., 2013, p. 81). Several students complained that Text B was not particularly clear, either, and I highlighted that there might possibly be an issue with over-use of the passive.

Finally, regarding trustworthiness, students were concerned about possible bias in Text A, and I suggested that this impression was heightened by a lack of appropriate modality; some statements, on the basis of limited evidence from what was a small-scale study, seemed far too certain; for example, "this paper concludes that cooperative group work is effective..." (Arumugam et al., 2013, p. 81). Always? Not an overgeneralization? In contrast, Text B appeared to demonstrate more appropriate academic caution, and I highlighted expressions in the final sentence that embodied this, such as "raise questions... suggest... may" (Beddoes \& Panther, 2017, p. 330). Also regarding trustworthiness, I explained that factors such as the evidence of peer review and the quality of the journal can be indicators of this; I highlighted that Text B seemed to be from a more reputable journal than Text $\mathrm{A}$.

Having introduced the students to textual analysis in class in this way, I then provided input on Grice's (1989) maxims, and related the analysis that they had just conducted to this framework, which may have benefited learners searching for a more holistic 
understanding of how academic texts communicate. As the course progressed, each of the maxims was, by turns, explored in more depth.

\section{METHODOLOGY}

To assess retrospectively what students felt they had gained from exploring academic writing through Grice (1989), I decided to analyze their reflective assessments (Assignment 5). The title was:

Reflect on what you have learned so far on this course about critically evaluating academic articles, focusing in-depth on a particular aspect of your learning. Use examples from your chosen article to support your points and draw on the literature as appropriate.

The qualitative data were coded manually, with themes regarding areas of impact identified. These themes seemed to fit with Grice's (1989) maxims and were categorized accordingly. Further clustering took place within themes, key quotes were identified and then the narrative picture, below, was developed. This blends quotes from students, to retain their authentic voices as far as possible, with paraphrases of their ideas and analytical commentary.

\section{RESULTS}

While the students' reflective writing needs to be interpreted cautiously since it had been produced for assessment, an analysis of what they reported they had learned about critically evaluating academic articles through the course is revealing. As is explained below, it is evident that input in different areas seems to have made an impression, although the extent to which this was deep rather than surface appears also inevitably to have varied across individuals.

The first of Grice's (1989) maxims they had drawn upon in critically evaluating their chosen articles during the course was Quantity; they had needed to consider how wellstructured and balanced the article was, and the extent to which an appropriate level of detail was provided in each section. For several students, this aspect of the critical evaluation was highlighted as having been particularly useful, for supporting "holistic understanding" (S7). S18 wrote, for example: "I think the most important thing that is necessary for every student to know are the main elements of the research report and the purpose of them". This student highlighted:

when I was in high school, they used to teach us only these three elements: introduction, body and conclusion. They did not tell us the rest of the elements that can be written in a research report such as abstract, methodology, discussion and results/findings (S18).

Besides having been introduced in school to an introduction-body-conclusion essay structure, this student reported she (for convenience all students will be referred to as 'she') had also been required to produce abstracts and results/findings sections in chemistry and physics lab reports. However, she had been unaware that she could "use those elements in other research articles" (S18). So, through this English and Communication 2 course, she had apparently developed some awareness of the constituent parts of research articles. An awareness of how these different elements 
functioned may also have been developed in these students. S7 reported, for example: "one should understand the motive of the study through the abstract", thus highlighting one key purpose. Students had also been encouraged to analyze whether each section contained an appropriate level of detail, apparently generating insights. For example, with reference to an academic article she had analyzed, which she felt had contained one overlong section, S16 wrote: "I realized that providing information blindly weakens the article enormously".

The second of Grice's (1989) maxims that was used for the basis of critical evaluation on the course was Relation; this was operationalized by asking the students to consider how well their chosen article established and maintained relevance and how well relevant literature was used to build an argument. Partly for cultural reasons, perhaps (Almalki, 2015), the notion of 'relevance' in a western sense appears to have been unfamiliar to some students. S12 reported, for example: "Before getting into this course, I didn't know that relevance is one of the main things that we should focus on when writing an academic article". S10 highlighted she had "learned that the literature and the ideas should relate to the main idea of the paper. Maintaining such relevance enables the reader to track down the ideas easily instead of feeling lost". This student then went on to explain how the article she had chosen to analyze had failed to maintain relevance at one specific point, continuing: "I realized that such an idea was too general, unnecessary and out of context, which may cause the reader to get confused or distracted". The importance of considering the needs of the reader was highlighted by another student, who had clearly assimilated some of the input on the peer review process academic articles go through: "the writers must follow a specific direction to fulfil the peer reviewer's instructions" (S14).

Other students highlighted what they had learned about referencing as a way of establishing relevance. S19 reported, for example: "Before this course, I was choosing random articles without looking for types of references used. Furthermore, I did not know about the strategies that could be used to reference, as my references were just direct quotes and paraphrases". Similarly, S13 indicated she had only known "about the direct quote referencing". Students demonstrated some awareness of the difference between integral referencing, when the citation, introduced by reporting verbs that "express an appropriate level of confidence" (S19), is grammatically part of the sentence and nonintegral referencing, with the in-text citation in parentheses at the end of the sentence. S6 distinguished between these two types by highlighting that in her chosen article nonintegral citations were used as a "foundation for arguments", while integral citations were used more to "explain" and "present" them, seemingly assigning these integral citations a more active role in driving the discourse forward. With reference to her article, S19 noted that "using integral citations draws attention to the author's important role in developing the information used, whereas non-integral citations give greater emphasis to the information provided". This reflected input (e.g. from Thompson \& Tribble, 2001) provided on the course. This student then went on to explain how she had tried to put what she had learned about referencing to immediate use in a humanities project for another course.

Other students highlighted that they had been particularly influenced by input on clarity, which was introduced in relation to Grice's (1989) maxim Manner. In evaluating their chosen articles, students had been asked to consider how clearly written they were overall, and the extent to which choices regarding voice (active/passive and personal/impersonal 
style) appeared to contribute to the clarity of the work. S2 became concerned about the over-use of jargon and acronyms in the article she was analyzing. She reported she had not paid much attention to these issues before, reflecting:

I thought that shortening the article, by writing the first letters of each word, will make the article easy for the reader to scan and read. Furthermore, in my essays, I used to include scientific words without explaining the meaning of the word, thinking that the readers would automatically know and understand such terms (S2).

Now, though after interacting with a text that was somewhat difficult to decipher, she argued: "Jargon and acronyms in articles can really diminish the capability of readers to relate to and understand the article they are reading" (S2). Poor academic practice in this regard also bothered S8, whose chosen article included an acronym, the full form of which did not appear until "the second half of the next page". This student also complained about overuse of the passive in the article analyzed, which, together with a complete lack of first person pronouns, even in the acknowledgements, made the article "feel impersonal at times" (S8). The academic articles which students had chosen, all from international journals of varying quality and with different editorial styles, apparently varied considerably in their use of the first person, as one would expect, since the first person, frowned upon in some contexts, can quite legitimately be present, particularly in certain subject areas of academic writing (Hyland, 2002), as has been highlighted above. S9 noted that there had been 41 first person pronouns in the article she had analyzed. This prompted her to reflect: "in my first English course at university, the instructors taught me that the first person pronoun 'I' is not allowed in academic articles. In contrast, I have learned the opposite in my second English course at the university" (S9).

Students' prior knowledge and assumptions were also challenged in a further way through this English and Communication 2 course. This was with regard to the last of Grice's (1989) maxims that was made the focus of critical analysis, the maxim Quality: "Try to make your contribution one which is true", which can be realized through more specific maxims: "Do not say what you believe to be false" and "Do not say that for which you lack adequate evidence" (Grice, 1989, p. 57). The students were specifically asked to consider the extent to which the use of modality contributed to the trustworthiness of their chosen article, and one, at least, found the notion of text demonstrating modality problematic, indicating, in the future, she would avoid work featuring this: "I will be sure to base my writing and research papers on accurately proven research and try to avoid the use of modal verbs to exclude uncertainty" (S3).

The reflections of other students suggest the input on modality helped them gain more nuanced understandings of issues of trustworthiness in research. S11 reported, for example: "Before taking the course, I did not know what does modality even mean, as I have not taken any courses in school or university that consider modality in academic articles". Before, she continued, she had read articles, "highlighting the evidence and facts, without caring about the level of certainty"; however, "there were signs", she concluded, "to indicate low and high modality that [she had] not noticed before" (S11). Similarly, S15 wrote that it helped her "view things from a different perspective", while S4 recalled her thinking processes:

I was surprised when the professor linked using those words to the paper's reliability. I thought how can modal expressions contribute to the reliability of an academic paper if the writer demonstrates a level of 
uncertainty? Afterwards, I learned that writers who do not use the modal words can receive criticism. Also, if any information was proven to be wrong, the writer might not be trusted again (S4).

Several students appreciated there were implications for practice. For example, S5 wrote: "practicing this evaluating method made me realize that I should become more cautious while stating ideas in my writing... otherwise, my paper will be weak and unreliable".

On a final note, in their introductions to their reflections, several students highlighted how the input in relation to the different maxims had worked together to develop competence in critically evaluating academic articles. One reflected, for example:

I have learned that when evaluating an article, it is essential to look for specific primary keys that determine the quality of the scholarly article. These primary keys include quantity, relevance, accessible writing style, and the quality of the information mentioned. In the beginning, I thought it was going to be tough and complicated, but after the instructor's assistance, I felt more confident and stimulated (S17).

While such a comment could be dismissed as an attempt to please the teacher, it is also perhaps worth noting that the course was highly rated in the independent evaluations provided by the students to the administration, and made accessible to the teacher (me) after administrative processing and analysis. Besides high scores overall (and much higher than departmental averages) on items eliciting satisfaction with the course and course delivery, the students provided positive qualitative comments, such as the following: "This class was fun, informative and I can say I learned so much..."

\section{CONCLUSIONS}

While the findings above are from just 19 students reflecting on one undergraduate English and Communication course centered on textual analysis supported by Grice's (1989) maxims, they do illustrate the benefits of such a pedagogical approach. To a certain extent, the results presented here confirm previous findings, in that Nunn (2009) highlighted development of students' critical thinking skills stimulated by engagement with academic texts through the use of Grice's (1989) maxims. At the same time, though, these results extend those findings, since while Nunn's (2009) analysis was based on his reading of students' critical engagement with texts, the data drawn upon in this study are students' reflections on having engaged in such critical analysis through four successive assignments centered on different maxims. So here it is the students' reflections that are primarily of interest. This is on the understanding that, while these reflections were produced for assessment, they might nevertheless provide insights into the students' longer-term learning processes.

Making Gricean pragmatics central to supporting the development of academic writing in this context seems to have been beneficial partly because the students' textual analyses were conducted with articles they had chosen, on topics they had selected, presumably out of intrinsic interest, to explore further for project work. Exploring these authentic academic texts in relation to Grice's maxims seemed to help the students on this English and Communication 2 course question prior assumptions and received knowledge. This led to reported insights, for example into the need for hedging in 
academic discourse or that using the first person was acceptable in some academic contexts or that excessive jargon could interfere with understanding. Interacting with academic texts seemed to enable students to gain a grasp of the article's structure and see how patterns of integral and non-integral references could advance an academic argument. At the same time, however, there was some resistance to a concept as important as hedging, with one student saying she would seek to eliminate this from her work; she perhaps needed more time to engage deeply with the idea. Nor was there a great deal in their reflections on relevance, except as to the newness of the concept. For cultural reasons (Almalki, 2015), the students may have needed more time to assimilate this idea. Nevertheless, in the context of a one-semester course, clear benefits in terms of learning are apparent. This suggests that, while it seems future versions of the course in this context will benefit from additional input on relevance from cross-cultural perspectives and more time spent on modality, the pedagogical approach adopted here seems worthy of further use, experimentation with and monitoring. It reflects a holistic approach to developing academic literary drawing on Gricean maxims and centered on an interactional theory of coherence that could also be appropriate for other contexts.

\section{REFERENCES}

Abari, A.F. \& Lofti, A.R. (2013). The Gricean maxim of quantity in academic texts: A study of English and Persian journal articles written by both native and non-native speakers. International Journal of Basic Sciences and Applied Research, 2(12), 10231029.

Almalki, H.S. (2015). How culturally situated notions of 'politeness' forms influence the way Saudi postgraduate students write academic English? Unpublished Masters' dissertation. Monash University, Australia. https://au-east.erc.monash.edu.au/fpfiles/7641943/monash_161311.pdf

Arumugam, N., Rafik-Galea, S., de Mello, G. \& Dass, L.C. (2013). Cultural influences on group learning in an ESL classroom. Review of European Studies, 5(2), 81-89.

http://www.ccsenet.org/journal/index.php/res/article/view/27829

Beddoes, K. \& Panther, G. (2017). Gender and teamwork: An analysis of professors' perspectives and practices. European Journal of Engineering Education, 43(3), 330-343. https://www.tandfonline.com/doi/abs/10.1080/03043797.2017.1367759

Grice, H.P. (1975). Logic and conversation. In Cole, P. \& Morgan, J.L. (eds.), Syntax and Semantics, Vol. 3, Speech Acts (pp. 41-58). New York: Academic Press.

Grice, H.P. (1989). Studies in the Way of Words. Cambridge, MA: Harvard University Press.

Hyland, K. (1994). Hedging in academic writing and EAP textbooks. English for Specific Purposes, 13(3), 239-256.

https://www.sciencedirect.com/science/article/pii/0889490694900043

Hyland, K. (2002). Options of identity in academic writing. ELT Journal, 56(4), 351-358. https://academic.oup.com/eltj/article-abstract/56/4/351/410117

Lee, I. (2002). Teaching coherence to ESL students: a classroom inquiry. Journal of Second Language Writing, 11, 135-159.

https://www.sciencedirect.com/science/article/pii/S1060374302000656 
Leech, G. (1983). Principles of Pragmatics. London: Longman.

McCarthy, M. (1991). Discourse Analysis for Language Teachers. Cambridge: Cambridge University Press.

Nunn, R. (2006). The pragmatics of cooperation and relevance for teaching and learning. The Linguistics Journal, 1, 5-16. http://www.linguistics-journal.com/wpcontent/uploads/2014/01/January2006_V1.pdf\#page=5

Nunn, R. (2009). Developing pragmatic competence for critical academic reading in Explorations in Cohen, R. (ed.), Explorations in second language reading. Alexandria, U.S.A.: TESOL International Publications, pp. 117-131.

Nunn, R. \& Deveci, T. (in press). 'Holistic argumentation creation': Integrated principles for helping graduate students create a journal paper. In J.N. Corcoran, L.M. Muresan, \& K. Englander (Eds.), Pedagogies and Policies on Publishing Research in English: Local Initiatives Supporting International Scholars. New York: Routledge.

Swales, J.M. \& Feak, C.B. (2009). Abstracts and the Writing of Abstracts. Michigan: University of Michigan Press.

Thompson, P. \& Tribble, C. (2001). Looking at citations: Using corpora in English for academic purposes. Language Learning Technology, 5(3), 91-105.

https://www.researchgate.net/profile/Paul_Thompson20/publication/220017768_Looking _at_citations_Using_corpora_in_English_for_Academic_Purposes/links/544e97da0cf 26dda0890173e.pdf

Tseng, M.Y. (2015). Describing creative products in an intercultural context: Toward a pragmatic and empirical account. Journal of Pragmatics, 80, 52-69.

https://www.sciencedirect.com/science/article/pii/S0378216615000703

White, R. (2001). Adapting Grice's maxims in the teaching of writing. ELT Journal, 55(1), 62-69. https://academic.oup.com/eltj/article-abstract/55/1/62/3114082

Wittgenstein, L. (2001 [1953]). Philosophical investigations. Oxford: Blackwell. 